\title{
Study of physico-chemical parameters of orange (Citrus reticulate Blanco) for the development of orange wine
}

\author{
S. R. Patharkar*, S. N. Shendge and A. P. Khapre \\ College of Food Technology, Naigaon, MIT College of Food Technology, Aurangabad (M.S.), INDIA \\ *Corresponding author. E-mail: khapreft@gmail.com
}

Received: November 18, 2016; Revised received: June 24, 2017; Accepted: October 23, 2017

Abstract: Physico-chemical properties are an essential factor during processing and preservation of food. The retention and changes in physico-chemical properties depends upon the processing technique. In this work, physicochemical parameters of orange like vitamin $\mathrm{C}$ (ascorbic acid), $\mathrm{pH}$, total soluble solids (TSS), \% acidity, temperature and color were studied with all the optimized conditions of fermentations for the development of orange wine. The fermentation of the fruit juice was completed within 7 days period at temperature $27^{\circ} \mathrm{C}, \mathrm{pH} 4.5$ and total soluble solids of $24^{\circ}$ Brix with an inoculum level of $10 \%(\mathrm{v} / \mathrm{v})$. Thus, orange wine with ethanol content of $8.5 \%(\mathrm{v} / \mathrm{v})$ was prepared from the orange variety 'Nagpur Santra' (Citrus Reticulata Blanco) in controlled physico-chemical parameters.

Keywords: Alcoholic fermentation, Orange juice, Physico-chemical parameters, Saccharomyces cerevisiae, Wine

\section{INTRODUCTION}

Oranges (Citrus reticulate Blanco) constituted by far the most important class of commercial citrus grown in the world (Joshi et al., 2000). A large portion of the world orange crop is used in the production of orange juice, which is probably the most popular fruit juice worldwide with pleasant flavor and color, and rich in nutritional and biological active compounds, such as potassium, vitamin $\mathrm{C}$ and amino acids. Global orange production for $2016 / 17$ is forecast up 2.4 million metric tons from the previous year to 49.6 million (USDA, 2017). The physical and chemical characteristics of most commercial orange varieties have been studied thoroughly (Park et al., 1983). Many agricultural reports like Indiana Wines Association (Indiana Wine Grape Council, IN 47907, 2002) and Oakville Winegrowers (Oakville, CA 94562, 2002) have been published about the chemical composition changes of oranges in relation to season, cultivar and geographic origin (Barry et al., 2003). Orange juice contains substantial amounts of several micronutrients such as vitamin C, folate and polyphenols (e.g. hesperidin which is a flavanone) and may therefore contribute significantly to their daily intakes (Galaverna and Dall'Asta, 2014). Citrus fruits are one of the few fruits of which all parts can be processed. The flesh can be juiced, canned or frozen. The skin can be dried or sugared or used for the production of oils. The white membranes are used for pectin production. In the case of oranges, the juice can also be fermented to produce orange wine. Fruit wines are undistilled alcoholic beverages usually made from grapes or other fruits such as peaches, plums or apricots, banana, elderberry or black current etc. which are nutritive, more tasty and mild stimulants. These fruits undergo a period of fermentation and ageing. They usually have an alcohol content ranging between 5 to13 percent (Joshi et al., 2000).

Wine has been evaluated to be able to impart better organoleptic quality by pure Saccharomyces cerevisiae (Imma et al., 2009). Oranges grown all over the world, in Asia, it is most abundantly grown in Japan, southern China and India. Now, with orange cultivation and orange-processing enterprises developing in India, the physicochemical characteristics of orange samples are urgently needed for better production and processing. Therefore, present work has been carried out to investigate the physicochemical parameters of orange juice required for the development of orange wine.

\section{MATERIALS AND METHODS}

Oranges: Orange variety 'Nagpur Santra' (Citrus Reticulata Blanco) was used in the study was purchased from the local market of Nagpur. Fresh ripened oranges were washed with water, peeled and juice was extracted using the screw press juice extractor.

Pretreatment of orange juice: The degree brix $\left({ }^{\circ} \mathrm{Bx}\right)$ of the orange juice was raised as required by adding sugar. $\mathrm{pH}$ was adjusted by adding a saturated solution of sodium bicarbonate. Then, it was pasteurized and allowed to cool to room temperature

Cultures: For the fermentation process, yeast strain Sacchromyces cerevisiae (CFTRI 102) was used and was obtained from National Chemical laboratory, Pune.

Preparation of broth: The broth media was prepared in 250 distilled water consisting of $0.75 \mathrm{~g}$ malt extract, $2.5 \mathrm{~g}$ glucose, $0.75 \mathrm{~g}$ yeast extract and $1.25 \mathrm{~g}$ of peptone. 
This media was sterilized and divided into different flasks to maintain a volume of $30 \mathrm{ml}$ then inoculated with the yeast strain and kept for incubation at $27^{\circ} \mathrm{C}$ for a day and then stored at low temperature (Garcia et al., 2006).

Batch fermentation set up: $500 \mathrm{ml}$ of pasteurized orange juice of $24^{0}$ Brix was taken in $1000 \mathrm{ml}$ conical flask and broth media is added under sterile conditions. Fermentation was carried out at $27^{\circ} \mathrm{C}$ under anaerobic condition with arrangement for $\mathrm{CO}_{2}$ to escape. After completion of fermentation the wine was filtered, centrifuged and filled in glass bottles (Robert, 2006).

Physico-chemical characterization of orange fruit and wine: Orange fruit and wine samples were analysed by using standard analytical procedures with AR grade chemicals and sophisticated laboratory equipments for various physico-chemical parameters.

Total soluble solids (TSS): The amount of sugar in wine grape influences potential alcohol content after fermentation, and the amount of residual sugars remaining in the wine. The Total Soluble Solids (TSS) in wine grapes is normally $99 \%$ sugars (glucose and fructose). It is thus a good assessment of sweetness, and prices are often based upon the TSS content in harvested grapes. The total soluble solid content was determined in terms of degree brix by using hand refractometer at $20^{\circ} \mathrm{C}\left(68^{\circ} \mathrm{F}\right)$. It measures TSS in terms of refractive index. Brix is a measure of solids only in case of pure sucrose solutions (Maziar, 2006).

pH: The $\mathrm{pH}$ of a wine is critical not only to its flavor but to nearly every aspect of the wine. According to wine maker Alison Crowe of Winemaker Magazine "pH is the backbone of a wine". The $\mathrm{pH}$ of juice was measured by using electronic digital $\mathrm{pH}$ meter (Ranganna, 1986).

Acidity: The acids in wine are an important component in both winemaking and the finished product of wine. They are present in both grapes and wine, having direct influences on the color, balance and taste of the wine as well as the growth and vitality of yeast during fermentation and protecting the wine from bacteria. For measuring acidity, the known quantity of sample was taken. Water was added to it and mixed thoroughly, finally made up to known volume. Then known amount of that extract was titrated with $0.1 \mathrm{~N} \mathrm{NaOH}$ using few drops of $1 \%$ phenolphthalein solution as indicator. The titre value was noted. The results were calculated as percent citric acid, as $1 \mathrm{ml}$ of $0.1 \mathrm{~N} \mathrm{NaOH}=0.0064 \mathrm{~g}$ citric acid (Ranganna, 1986). $\%$ Acidity $=(0.0064 \times \mathrm{N}$ of $\mathrm{NaOH} \times$ Volume made up $\times$ B.R. $\times 100) /($ Volume of sample taken $\times$ weight of sample×1000)

Ascorbic acid: Ascorbic acid $(\mathrm{mg} / 100 \mathrm{ml})$ content was estimated by oxidation standard dye method (Ranganna, 1986).

Juice yield: The percent yield of juice was calculated on the basis of weight of total weight of fruits (Nikhil et al., 2009).
Percent yield $=($ Weight of juice $) /($ Total weight of fruit $)$ $\times 100$

Juice clarity: It reflects the consumer acceptability of wine. The clarity of juice was determined by measuring the absorbance at a wavelength of $660 \mathrm{~nm}$ using UV-VIS spectrophotometer (\% Absorbance). Distilled water was used as the reference.

Waste index: Waste index of fruit was calculated by weighing waste portion and percent was calculated (Ranganna, 1986). The percent waste was calculated as follows:

Percent waste $=($ Weight of waste $) /($ Total wt of fruit $) \times$ 100

Specific gravity: The specific gravity was determined using specific gravity bottle. By considering the specific gravity, the brewer or vintner obtains an indication as to the probable ultimate alcoholic content of their product. The empty bottle was weighed, filled with distilled water and reweighed. It was then filled with sample and weighed (Ranganna, 1986). The specific gravity, of the sample was calculated, as follows: Specific Gravity $=$ Ws $/$ Ww

Where, $\mathrm{W}_{\mathrm{s}}=$ Weight of known volume of sample in gm $\mathrm{W}_{\mathrm{w}}=$ Weight of an equal volume of water in $\mathrm{gm}$

The density, $\rho$ in $\mathrm{kg} / \mathrm{m} 3$, was calculated as: $\rho=1000 \mathrm{x}$ Specific gravity

Alcohol (Ethanol): Alcohol was estimated volumetrically by oxidation method (Okunowo and Osuntoki, 2007) using Micro-Kjeldahl distillation apparatus.

Reducing sugars: Reducing sugars react with amino acids in the Maillard reaction, a series of reactions that occurs while cooking food at high temperatures and that is important in determining the flavor of food. Also, the levels of reducing sugars in wine are indicative of the quality of these food products. Lane and Eynon constant titre method was used. Mixed Fehling's solution is titrated with sample using methylene blue as indicator (AOAC, 1980).

\section{RESULTS AND DISCUSSION}

Orange fruit analysed for various physico-chemical parameters (Table 1) using standard analytical procedures. The TSS of grape fruit was $11.4^{0} \mathrm{Brix}$, which indicate that fruits were suitable for fermentation.

Optimized conditions of fermentations and physicochemical analysis of orange wine: In fermentation study, there are 4 batches of orange juice were used in which the optimal fermentative conditions were used for the production of orange wine such as total soluble solids (TSS ${ }^{\circ}$ Brix), inoculum level (v/v), $\mathrm{pH}$ and temperature. The results of the fermentation confirmed that $S$. cerevisiae was capable of completely fermenting the orange juice after 7 days (Figs. 1 to 4 ). The chemical composition of wine is presented in Table 2 . The highest alcohol \% was obtained in Batch IV wine sample at optimized conditions of fermentations like $10 \%$ inoculums level, $24^{\circ} \mathrm{Brix}$ of total soluble solids, 
S.R. Patharkar et al. / J. Appl. \& Nat. Sci. 9 (4): 2305 - 2308 (2017)

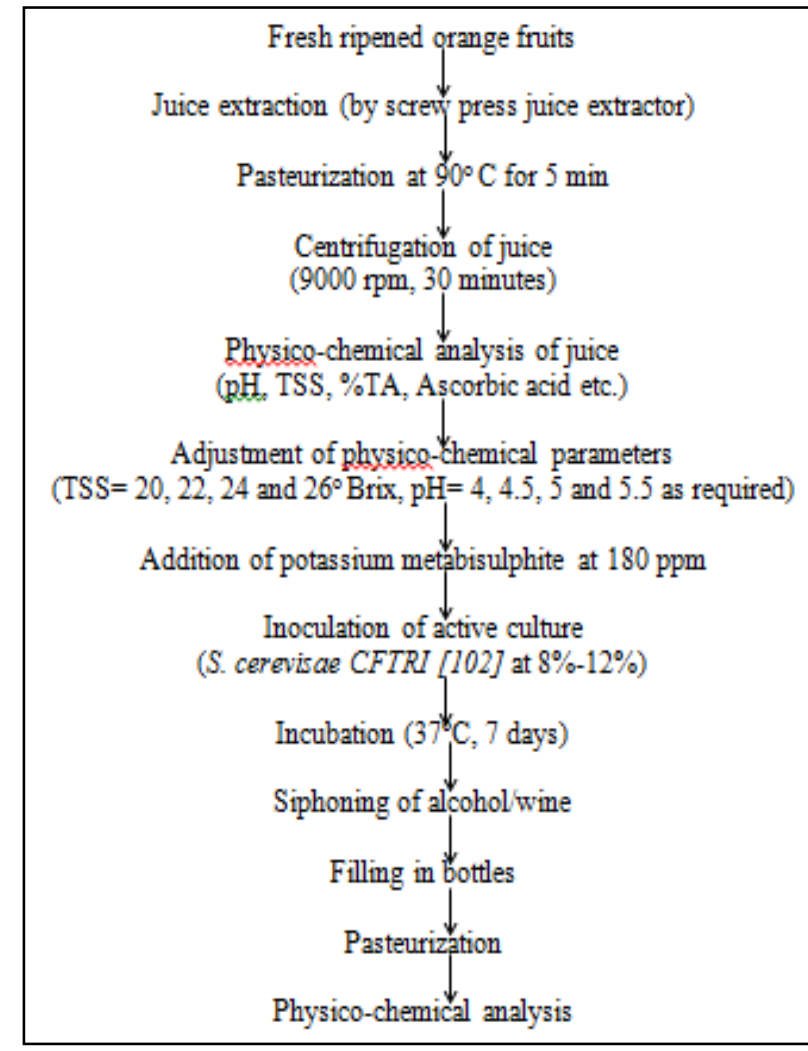

Flow diagram for the preparation orange wine.

Table 1. Physico-chemical analysis of orange.

\begin{tabular}{lll}
\hline S. N. & Parameter & Value \\
\hline 1 & Average weight $(\mathrm{g})$ & 120 \\
2 & Height/Length $(\mathrm{cm})$ & 5.5 \\
3 & Diameter $(\mathrm{cm})$ & 6.2 \\
4 & Pomace $(\%)$ & 24 \\
5 & Pulp (\%) & 45 \\
6 & Peel (\%) & 29 \\
7 & TSS ( ${ }^{\circ}$ Brix) & 11.4 \\
8 & pH & 3.4 \\
9 & Specific gravity & 1.014 \\
10 & Clarity (\% Absorbance) & 0.278 \\
11 & Acidity (as \% anhydrous citric acid) & 0.63 \\
12 & Ascorbic Acid (mg/100 ml) & 35 \\
13 & Reducing sugar (mg/100ml) & 3.23 \\
\hline
\end{tabular}

Each value is an average of three replications.

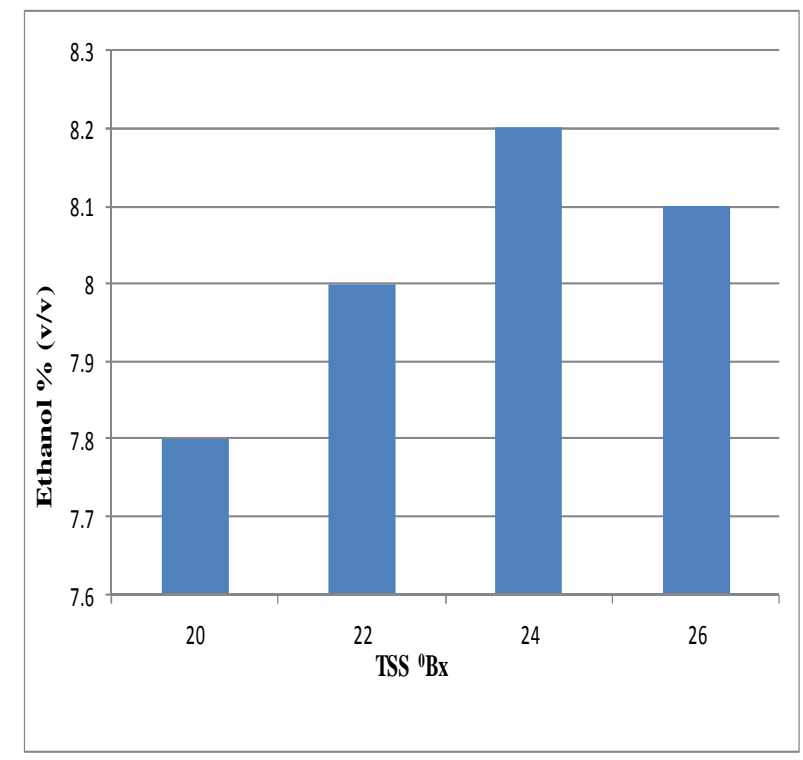

Fig. 1. Optimization of orange wine with total soluble solids as fermentation condition (Fermentation conditions: Adjusted pH: 4.5; inoculum level: $10 \%(\mathrm{v} / \mathrm{v})$;temperature: $27^{\circ}$ C; fermentation time: 7 days).

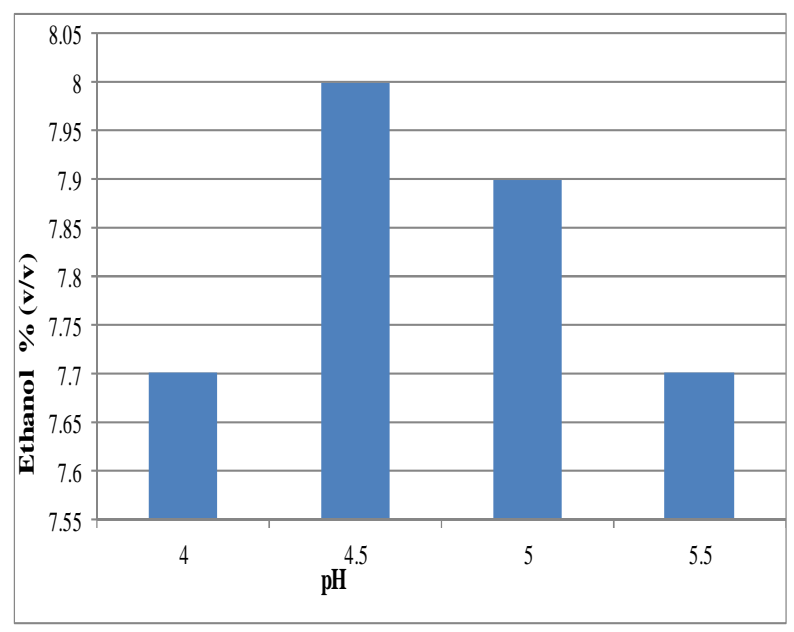

Fig. 2. Optimization of orange wine with $\mathrm{pH}$ as fermentation condition (Fermentation conditions: Total soluble solids: $24^{\circ} \mathrm{Bx}$; inoculum level: $10 \%(\mathrm{v} / \mathrm{v})$, temperature: $27^{\circ} \mathrm{C}$; fermentation time: 7 days).

Table 2. Physico-chemical analysis of orange wine.

\begin{tabular}{llllll}
\hline Composition & Batch I & Batch II & Batch III & Batch IV & Mean \\
\hline Initial TSS $\left({ }^{\circ}\right.$ Brix) & 24 & 24 & 24 & 24 & 24 \\
Final TSS( $\left({ }^{\circ}\right.$ Brix) & 8.4 & 9.4 & 9 & 8 & 8.7 \\
Acidity (\% citric acid) & 0.61 & 0.63 & 0.67 & 0.65 & 0.64 \\
Reducing sugars (\%) & 2.36 & 2.17 & 2.11 & 2.28 & 2.23 \\
Ascorbic acid(mg/100g) & 28.5 & 29 & 27 & 30 & 28.6 \\
Alcohol (\%) & 8.2 & 8 & 8.2 & 8.5 & 8.23 \\
Initial pH & 4.5 & 4.5 & 4.5 & 4.5 & 4.5 \\
Final pH & 3.0 & 3.2 & 3.1 & 2.8 & 3.03 \\
Inoculum level $(\%)$ & 10 & 10 & 10 & 10 & 10 \\
Specific gravity & 1.015 & 1.012 & 1.013 & 1.030 & 1.018 \\
Clarity (\% Absorbance) & 0.1860 & 0.1884 & 0.1882 & 0.1880 & 0.1877 \\
Fermentation temperature $\left({ }^{\circ} \mathrm{C}\right)$ & 27 & 27 & 27 & 27 & 27 \\
\hline
\end{tabular}

Each value is an average of three replications 


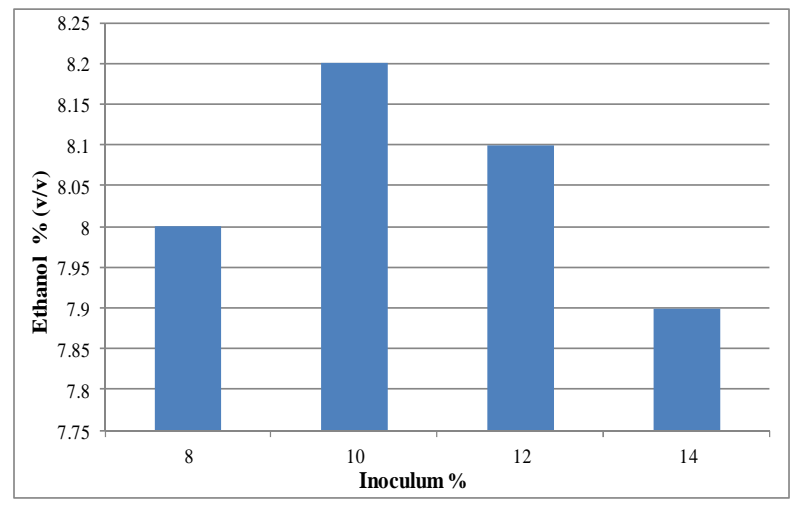

Fig. 3. Optimization of orange wine with percent inoculum as fermentation condition (Fermentation conditions: Total soluble solids: $24^{\circ} \mathrm{Bx}$; $\mathrm{pH}$ : 4.5 ; temperature: $27^{\circ} \mathrm{C}$; fermentation time: 7 days).

$4.5 \mathrm{pH}$ and $27^{\circ} \mathrm{C}$ temperature. [Gavimath et al. (2012) found that the final TSS and $\mathrm{pH}$ after one month of aging in orange wine varied between $14^{\circ} \mathrm{Brix}$ to $12^{\circ}$ Brix and 5 to 3 , respectively. Branco et al. (2007) also observed that $\mathrm{pH}$, total acidity and soluble solids of the orange juice were nearly similar to those found in the literature, which were $3.54,1.23 \mathrm{~g} / 100 \mathrm{~mL}$ and $10{ }^{\circ} \mathrm{Brix}$, respectively as compare to the orange wine values were $3.03,0.64$ and 8.7 of $\mathrm{pH}$, total acidity and soluble solids respectively].

\section{Conclusion}

In this work, orange variety 'Nagpur Santra' (Citrus Reticulata Blanco) was used for wine preparation. Orange wine with ethanol content of $8.5 \%(\mathrm{v} / \mathrm{v})$ was prepared using in 7 days of fermentation period at temperature $27^{\circ} \mathrm{C}, \mathrm{pH} 4.5$ and total soluble solids of $24^{\mathrm{o}-}$ Brix with an inoculum level of $10 \%(\mathrm{v} / \mathrm{v})$. The wine sample has also recorded 1.030 specific gravity, 30 $\mathrm{mg} / 100 \mathrm{~g}$ ascorbic acid and $0.1880 \%$ absorbance. Therefore, prepared orange wine has acceptable physico-chemical parameters with good sensory appeal

\section{REFERENCES}

AOAC. (1980). Association of official Analytical chemist, Official methods of analysis. Hortwitz, W. (ed.), $13^{\text {th }}$ edn. Washington, D.C. p. 1015

Barry, G.H., Castle, W.S. and Davies, F.S. (2003). Variability in juice quality of Valencia sweet orange and sample size estimation for juice quality experiments. Journal of American Society for Horticultural Science, 128: 803-808

Branco, I.G., Sanjinez-Argandoña, E.J., Silva, M.M. and Paula, T.M. (2007). Sensorial evaluation and physicalchemical stability of a blend of orange and carrot. Ciência e Tecnologia de Alimentos, 27(1), 7-12

Galaverna, G. and Dall'Asta, C. (2014). Production processes of Orange juice and effectson antioxidant components.In: Preedy, V.R., Ed., Processing and impact on antioxidants in beverages, Elsevier, Amsterdam, 203214.

Garcia, V., H. Vasquez and F. Fonseca. (2006). Effects of

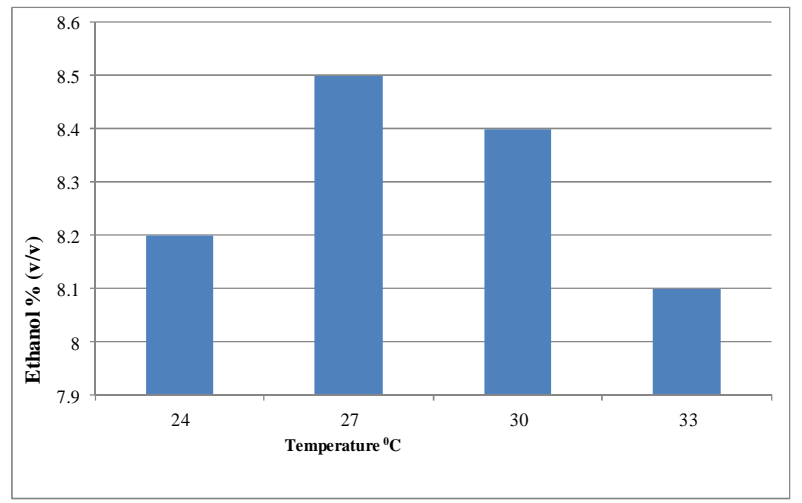

Fig. 4. Optimization of orange wine with temperature as fermentation condition (Fermentation conditions: Total soluble solids: $24^{\circ} \mathrm{Bx} ; \mathrm{pH} 4.5$, inoculum level: $10 \%$; fermentation time: 7 days).

using mixed wine yeast cultures in the production of Chardonnay wines. Revista Argentina de Microbiology, 42: 226-229.

Gavimath, C. C., Kalsekar, D.P., Raorane, C.J., Kulkarni, S. M., Gavade, B. G., Ravishankar, B.E. and Hooli, V.R. (2012). Comparative analysis of wine from different fruits. International Journal of Advanced Biotechnology and Research, 3 (4): 810-813.

Imma Andorra, Maria Berradre, Nicolas Rozes, Albert Mas and Jose, M. Guillamón (2009). Effect of pure and mixed cultures of the main wine yeast species on grape must fermentations. Department of Biotechnology, University of Rovira, Tarragona, Spain.

Joshi, V.K., Sandhu, D.K. and Thakur, N.S. (2000). Fruit based alcoholic beverages. In Biotechnology: FoodFermentation,Vol. II. V.K. Joshi and Ashok Pandey (eds), pp. 647-732.

Maziar Safaei Asli (2006). A study on some efficient parameters in batch fermentation of ethanol using SaccharomycescerevesiaeSC1 extracted from fermented siahesardasht pomace.African Journal of Biotechnology, Vol. 9 (20): 2906-2912.

Nikhil Gupta, Soham Trivedi, Hipal Gaudani, Mayank Gupta, Prasad Patil and Girish Gupta. (2009).Orange: Research analysis for wine study.International Journal of Biotechnology Applications, Vol. 1, Issue 2, pp. 1015.

Okunowo, Wahab Oluwanisola and Osuntoki, Akinniyi Adediran. (2007). Quantitation of alcohols in orange wine fermented by four strains of yeast.African Journal of BiochemistryResearch, Vol.1 (6): 95-100.

Park, G.L, Byers, J.L., Pritz, C.M., Nelson, D.B., Navarro, J.L., Smolensky, D.C. and Vandercook, C.E. (1983). Characteristics of California navel orange juice and pulp wash. Journal of Food Science, 48: 627-632, 651.

Ranganna, S. (1986) Handbook of Analysis and Quality control for fruit and vegetable products. II edn. Tata McGraw-Hill Publ. Co., New Delhi.

Robert W. Hutkins. (2006). Microbiology and technology of fermented foods. I ${ }^{\text {st }}$ edition, 2006.

USDA. (2017). Citrus: World Markets and Trade. United States Department of Agriculture, Foreign Agricultural Service, January 2017. 